\title{
UNA APROXIMACIÓN RETÓRICA \\ A LOS MEMES DE INTERNET
}

\author{
A RETHORICAL APPROACH \\ TO INTERNET MEMES
}

\author{
José Manuel RUIZ MARTÍNEZ \\ jmanuelruiz@ugr.es
}

Resumen: El artículo constituye una aproximación al fenómeno actual de los llamados memes de Internet como objetos semióticos complejos que presta una atención especial a sus principales cualidades retóricas y, por ende, a su potencial persuasivo en la conversación pública.

Palabras clave: Memes. Internet. Retórica. Retórica visual.

Abstract: The paper is an approach to the Internet memes understood as complex semiotic objects. We will pay special attention to their main rhetorical devices, and therefore to their persuasive potential in public conversation nowdays.

Key Words: Memes. Internet. Rhetoric. Visual Rhetoric.

\section{INTRODUCCIÓN}

Los llamados memes de internet están cobrando cada vez mayor importancia en la comunicación contemporánea. Aparte de su medio de 
difusión natural, la red, incluso los medios de comunicación convencionales comienzan a hacerse eco de los más populares ${ }^{1}$. Cuando se produce algún acontecimiento que suscita la atención pública, en especial si tiene algún tinte sorprendente, casi de inmediato comienzan a proliferar y difundirse los consiguientes memes. Shifmann denomina a este impulso actual "hypermemetic logic, in which almost every major public event sprouts a stream of memes" (2014: 128; cursiva del autor). Entendidos de esta forma primera e intuitiva, los memes podrían percibirse como meros chistes gráficos que se popularizan a través de internet. No obstante, los memes son una realidad semiótica y retórica más compleja de lo que podría parecer. Más allá de su aparente trivialidad (que se da), los memes están contribuyendo a articular el discurso público en la actualidad, y sirven para conformar y reflejar estados de opinión (Shifman, 2014: 123), no solo en una dimensión meramente lúdica (lo que, por otra parte, no deja de tener su importancia en nuestra sociedad del entretenimiento y del espectáculo), sino también, y de manera especial, en el ámbito ideológico: los memes contribuyen a la discusión política pública. El auge y la popularidad de movimientos recientes como el llamado 15M, o el de Occupy Wall Street en EE.UU. (Milner, 2013), o del partido político Podemos, se explican en parte por la creación y difusión de memes a través de Internet con una deliberada intención propagandística — sin que implique connotaciones necesariamente peyorativas - y una eficaz dimensión retórica ${ }^{2}$. El debate en redes sociales en torno a los últimos procesos electorales habidos en España se ha articulado en cierta medida alrededor de memes de todo signo político. El escritor Jorge Bustos, aun con una hipérbole retórica y provocativa propia de una columna periodística, escribió hace poco que España era "una democracia consagrada al meme" (Bustos, 2016). Los memes de Internet constituyen, en definitiva, según Milner, una forma de capital cultural "as a realization of speech act force, as a mode of naturalizing and familiarizing social realities, as an instrument of authority, and as the medium (and the measure) of political debate"

1. El diario El País, por ejemplo, en su edición digital tiene una sección titulada "Verne" sobre Internet y redes sociales que dedica buena parte de su espacio a mostrar y comentar los memes más importantes del momento. $<$ http://verne.elpais.com $>$.

2. En el texto de Ignacio Pato (2016) aparecido en la revista online Playground y titulado significativamente "Podíamos, o cómo conquistar el Estado con memes y lágrimas" se vincula el uso de memes por el partido Podemos a una lucha por la hegemonía cultural en el sentido gramsciano del término. Internet sería un espacio que la hegemonía cultural dominante no controla del todo y desde donde se le puede oponer una resistencia en forma de guerra cultural. Y una herramienta para ello son los memes. 
(Hank apud. Milner, 2012: 16), y parecen cifrar algunas de las principales características de la comunicación en la cultura digital: así parecen haberlo intuido los millones de personas que a diario comparten, crean y recrean memes (Shifman, 2014: 123). De este modo, comprender qué es y cómo funciona un meme no es solo útil para entender una importante tendencia cultural y comunicativa actual, sino el propio funcionamiento de lo que se ha dado en llamar la web 2.0 $0^{3}$, de la que los memes constituyen un genuino epítome.

El propósito del presente artículo es, a partir de algunos de los principales textos de la creciente bibliografía especializada sobre el tema, entender los memes de internet como objetos semióticos de carácter multimedia y una technē eminentemente retórica ${ }^{4}$, que cumplen una función lúdica y en muchas ocasiones de carácter deliberadamente ideológica, y mostrar sus principales características y estrategias en este sentido. Pero antes es preciso aclarar, en la medida de lo posible dado lo ambiguo y embrionario aún del término, qué es un meme de internet.

\section{EL CONCEPTO GENERAL DE MEME}

A la hora de definir un meme de internet es preciso remitirse (como hace toda la bibliografía consultada sin excepción ${ }^{5}$ ) al concepto general de meme acuñado por Richard Dawkins en su libro El gen egoísta (Dawkins, 2002: 247-262). Un meme sería el equivalente cultural de un gen biológico ${ }^{6}$; según esto, se trata de una unidad de cultura capaz de transmitirse y sobrevivir en un determinado ecosistema social, y, como los genes, sufrir mutaciones, conjugarse con otros memes para formar unidades culturales más complejas (que Dawkins denomina memeplexes) o, en un momento dado, extinguirse por el empuje de otros memes o memeplexes más fuertes que ellos. Los memes se caracterizarían por tener tres propiedades básicas (Shifman, 2014: 240): longevidad (capacidad para mantenerse en el tiempo); fecundidad (capacidad para reproducirse); y fidelidad al original

3. La web 2.0 es aquella en la que los usuarios pueden participar, aportar contenido y crear páginas a través interfaces fáciles de usar (blogs, redes sociales, etc.) a diferencia del modelo anterior de web, donde el usuario principalmente era el receptor de un contenido subido a la red por programadores especializados.

4. Para las relaciones entre retórica y web 2.0 puede consultarse Berlanga et alii, 2016.

5. En efecto, todas las referencias de la bibliografía final que versan de manera específica sobre memes (lo que puede deducirse por los títulos), llevan una referencia a la definición y por ende al libro de Dawkins.

6. Nótese que estamos, por tanto, ante un concepto metafórico. Un constructo cultural, aunque algunos científicos tratan de otorgarle un valor literal y empírico (ver nota 10). 
en la transmisión (de forma que, a través de las variantes, el núcleo de información permanece). Un ejemplo sencillo de meme son los refranes, que consiguen transmitirse a través de las generaciones como supuestas fórmulas de sabiduría popular, y que pueden además sufrir actualizaciones o parodias que no son sino una prueba de su conocimiento generalizado. También los chistes, que se transmiten y se reelaboran continuamente, en ocasiones a partir de relatos más antiguos ignorados por quienes los cuentan ${ }^{7}$. El bautismo o el matrimonio serían memes que contribuyen a formar el memeplexe del cristianismo (las religiones serían memeplexes). La democracia o el nacionalismo también son memeplexes. La idea de meme como unidad cultural que se disemina a través de los sujetos sin una participación necesariamente consciente de estos serviría para explicar, de hecho, por qué algunas personas, sin ser creyentes, se casan por la Iglesia o bautizan a sus hijos: el meme, como suerte de gen cultural, se estaría reproduciendo a través de ellos ${ }^{8}$. Determinadas imágenes, que en el lenguaje coloquial se denominan "icónicas" (Jenkins, 2014: 444), esto es, reconocibles por una amplia mayoría de personas y sujetas además a variaciones, modificaciones y parodias con intenciones diversas, como la Mona lisa o los soldados alzando la bandera de los EE.UU. tras la batalla de Iwo-Jima, son memes. Este último ejemplo de las imágenes significativas empieza de hecho a aproximarse a la idea de meme de internet ${ }^{9}$. Como es lógico, el concepto de meme de Dawkins ha suscitado mucha controversia tanto en la comunidad biológica como en la de otros ámbitos culturales como la antropología, la psicología o la comunicación ${ }^{10}$, polémica que escapa del propósito del presente artículo. Pero sea como fuere, este es el origen de que, por analogía (o más bien sinécdoque), a los memes de Internet se les conozca así; en realidad simplemente como memes, según los denominaremos a partir de ahora.

7. Todavía circula hoy un chiste que es una reelaboración de la disputa entre griegos y romanos de $\mathrm{El}$ libro del buen Amor.

8. La cuestión de hasta qué punto los memes "utilizan" a los seres humanos para sobrevivir (como harían nuestros propios genes, o los virus), o en qué medida éstos controlan a los memes para expandir de forma deliberada determinadas ideas es una cuestión controvertida: vid. Shifman, 2014: 203-209; Rowan, 2015: 133146; Rodríguez, 2013 (constituye la tesis general del libro).

9. Ya hemos empleado dos veces el término parodia, que, como veremos, es fundamental para entenderlos, dado que la parodia es una forma de difusión y reconocimiento de un ítem cultural.

10 El libro sobre la teoría de los memes que más controversia ha suscitado ha sido el de Susan Blackmore, The Meme Machine (2000), donde sostiene unas tesis radicalmente empíricas y deterministas sobre los memes. Ver, por ejemplo, Shifman, 2014:179-192. 


\section{LOS MEMES DE INTERNET}

Davidson define un meme de internet como "a piece of culture, typically a joke, which gains influence trhough online transmission" (2012: 122). Esta "pieza de cultura" puede tratarse "de una imagen, un vídeo, una música, una frase" (García Huerta, 2014). Aquí encontramos las características básicas: un elemento cultural (cabría añadir, con una intención comunicativa); casi siempre una broma (los memes en buena medida tienen algún componente humorístico, o al menos que se pretende ingenioso); y, finalmente, el hecho de que se crean para difundirse a través de la web, lo que les confiere unas enormes posibilidades de extenderse con rapidez, y en su potencial para lograrlo se cifra su éxito, que depende de su kairos retórico de partida, esto es, su sentido de la oportunidad en relación a un contexto, a su capacidad para reflejar o responder a una realidad social. No obstante, los memes tienen otra cualidad fundamental: además de compartirse, se van alterando de forma deliberada en el proceso: los distintos usuarios se reapropian de ellos y los modifican para adaptarlos a sus necesidades comunicativas particulares. Esto se inserta en movimiento más amplio característico de la web 2.0 (ver nota 3) en la que, no solo compartir, sino imitar, reapropiarse y remezclar son valores fundamentales de lo que se ha denominado la "nueva cultura participativa" (Shifman, 2014: 297; Jenkins, 2013). En este sentido, los memes tienen un origen incierto, anónimo, eminentemente popular, como los chistes o los cuentos folklóricos - tradicionales o urbanos-(Shifman, 2014: 226): no hay autoría ni cita, y los receptores se sienten libres de reproducirlos y apropiárselos y modificarlos libremente a su vez ${ }^{11}$. La principal diferencia con aquéllos estriba en la capacidad de los memes para difundirse debido a su medio, y también en que los cambios y modificaciones que realizan los usuarios en el proceso de reproducción son más abundantes, sustanciales y deliberados: hay una clara voluntad de cambio y reutilización por parte de quienes los difunden. Un meme por tanto tiene que ser fácil de compartir (una acción especialmente sencilla en las distintas redes sociales, cuyas interfaces presentan herramientas específicas y de uso inmediato para ello); además, también tiene que ser fácil de modificar antes ser compartido (si

11. Existe una página que es una de las principales fuentes de los estudiosos del meme, que intenta realizar una suerte de arqueología de los memes más exitosos de internet tratando de rastrear su origen y de recoger todas las variantes posibles. Se llama Know your meme.: http://www.knowyourmeme.com. 
bien para esto ya se requiere cierto conocimiento especializado) ${ }^{12}$. Pero no sólo debe ser fácil de modificar en un sentido técnico; también, y esto es más importante, desde el punto de vista semiótico: un meme tiene que tener una forma, una estructura comunicativa que haga que su reutilización por los distintos receptores, que se convierten por tanto en emisores a su vez, les resulte comunicativamente útil. En resumen, para que un meme tenga éxito tiene que ser comunicable y maleable a la vez (Davidson, 2012: 124126); ambas cualidades garantizan su difusión: una en un sentido espacial (mucha gente lo difunde), y otra en un sentido temporal (mucha gente se reapropia de él y es capaz de encontrarle nuevos sentidos y usos, por lo que el meme permanece en el tiempo, no se pasa de moda).

Por su parte, Milner describe los memes de internet como construcciones discursivas que sirven para articular argumentaciones (Milner, 2012: 26), con lo que al humor se añade la cualidad de los memes para transmitir con éxito ciertas ideas y ser en sí mismos formas de argumentación. Finalmente, Limor Shifman, en la que es quizá la definición más precisa y extendida, identifica los memes como "(a) a group of digital item sharing in commom characteristics [...] (b) that were created with awarenes of each other, and (c) were circulated, imitated, and/or transformed via the internet by many users" (2014: 456). En este caso, aparte de la idea de la circulación, la imitación y la posibilidad de ser transformados, ya dichas, se destaca sobre todo el hecho de que estos "elementos digitales", en cuanto memes, no son unidades, sino grupos que comparten cualidades comunes (a continuación veremos cuáles señala Shifman): un único objeto semiótico digital no es un meme per se hasta que no se identifica con otros en función de unas determinadas características compartidas; un meme no es tanto un objeto comunicativo concreto, acabado, como un suerte de estructura semiótica capaz de ser utilizada, actualizada por los usuarios. No son objetos aislados, cerrados, sino constelaciones (Rowan, 2015: 797): hay que entender los memes como "objetos-proceso. Elementos abiertos que van mutando a través de micro-repeticiones y micro-diferencias" (Rowan, 2015: 127). Por tanto, "el meme no es nunca el objeto con el que te encuentras, que siempre será una posible manifestación de un meme, sino toda la constelación de

12. No obstante, ya existen diversas páginas web donde un usuario puede fácilmente reapropiarse de multitud de memes existentes para crear su propia variante de un modo sencillo, a través de plantillas. 
objetos que dan sentido a ese meme" (Rowan, 2015: 810). En definitiva, "the identification of memes relies on the identification of replications" (Davidson, 2012: 130). Aquí podría establecerse una analogía con el modelo de verso (verse design) y con el ejemplo de verso (verse instance) de Jakobson, donde el modelo "determina los rasgos invariantes de los ejemplos [...] y establece los límites de sus variaciones." (Jakobson, 1958: 51). Shifman menciona de hecho de forma explícita el concepto de meme instance, como una versión concreta de la plantilla memética del grupo en cuestión. (Nissenbaum, 2015: 2). Un meme no es solo contenido, sino también (o más bien) una "actuación” (Goriunova, 2013).

Davidson (2010: 123) considera que en los memes se puede distinguir la "manifestación", que sería el conjunto de objetos distintos a que da lugar el meme (podríamos decir sus actualizaciones); la "conducta", que son las acciones que los distintos individuos realizan con objeto de que el meme sobreviva y se difunda (compartirlo tal y como lo reciben, manipularlo antes de compartirlo, crear uno a partir del recibido...); y, finalmente, la idea o concepto que subyace al meme. Para Shifman (2014: 146-153), por su parte, las características que comparten los memes son las más tradicionales de "contenido", esto es, las idea o argumento que porta el meme, la "forma" en que esta idea se presenta; y, por último, la "stance": la actitud del receptor/difusor ante el meme (relacionada con la idea de la conducta de Davidson): su asentimiento ante éste, que lo lleva a compartirlo sin más; o su disentimiento, que puede llevar a la creación de un contrameme, esto es, un texto o artefacto con los mismo elementos estructurales pero con un contenido diametralmente opuesto, a veces por ironía; o bien sencillamente la reapropiación de la forma o contenido del meme para otros fines distintos de la versión que recibió.

Veamos un primer ejemplo. Durante la Segunda Guerra Mundial en el Reino Unido se hizo un cartel de seguridad acerca de los bombardeos; con un diseño tipográfico sobrio y elegante, en él se recomendaba que, en caso de ataque (elemento que se elude en el cartel, se da por sabido), se mantuviera la calma y se siguiera adelante ("Keep calm, and carry on"). En el año 2000, una librería londinense recuperó el cartel, que pronto comenzó a difundirse a través de Internet y comenzaron las primeras variantes hasta un número casi inabarcable ${ }^{13}$. Vemos que la forma principal de variante

13. Para hacerse una idea, puede consultarse la citada web knowyourmeme.com. 
consiste en sustituir la segunda parte del mensaje (el carry on, esto es, el "seguir adelante") por alguna actividad particular que se desea promover; no obstante, pronto encontramos desvíos más claramente humorísticos y absurdos, incluida la denegación del mensaje original, esto es, negarse a mantener la calma, o una suerte de metameme donde se alude al propio meme; por último, también otros con una clara intencionalidad política o ideológica, como es el caso del que denuncia el robo de datos por parte de Google, u otro en relación a la independencia de Escocia (que, habida cuenta de que el origen del cartel el propio Estado simbolizado por la corona presente en el cartel, genera una relación intertextual pertinente).

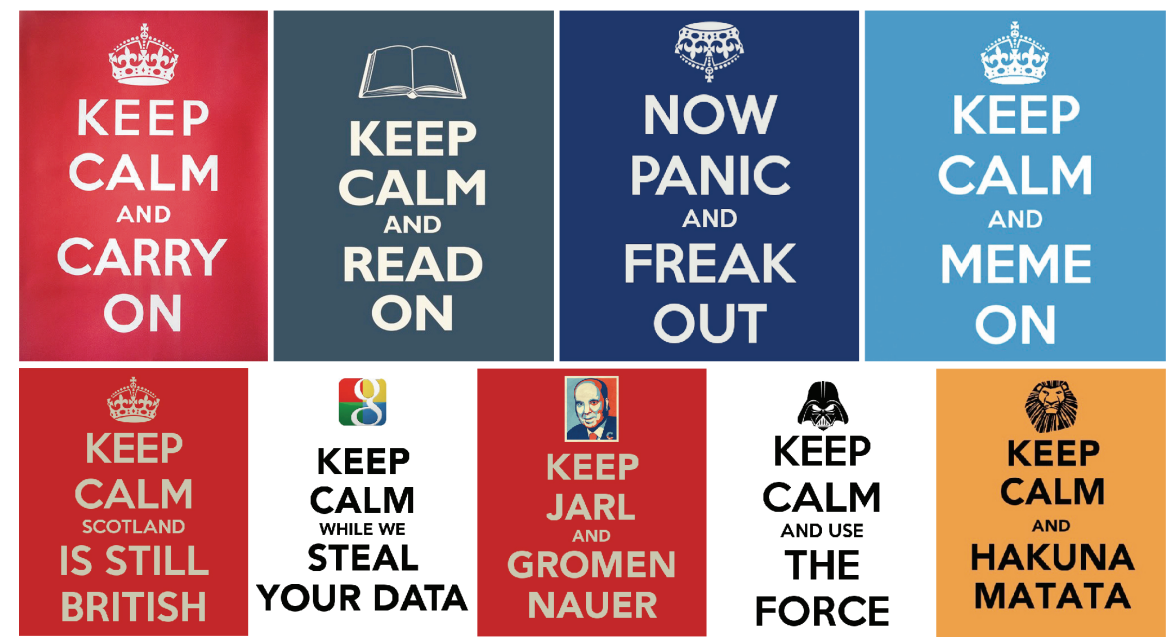

Desde el punto de vista de los elementos comunicativos visuales, encontramos en las variantes una sustitución de la corona original por otro símbolo representativo de la nueva realidad a la que se alude ahora (el logotipo de Google, por ejemplo). El conjunto de todas estas imágenes constituye, por usar la metáfora de Rowan, la constelación de un meme conocido como Keep calm. Ni la imagen original ni cada una de las variantes que circulan son memes; lo es la estructura semiótica que emerge del reconocimiento del modelo en las variantes, que es, en definitiva, lo que se está propagando al margen del contenido, la intención del usuario o incluso algunos rasgos formales menores, por emplear la tríada de 
características de Shifman. De ahí que sea preferible hablar de memética o de proceso memético antes que de memes como objetos (Milner, 2015). A partir de aquí, no resulta difícil discernir las distintas cualidades descritas por Davidson y Shifman: las distintas manifestaciones del meme, los actos de reapropiación y reformulación de las variantes; la "idea" o "contenido" del meme que, en este caso, podría resumirse como, "a pesar de todas las dificultades es preciso seguir adelante"; la forma (un símbolo en la parte superior, un fondo, una frase una tipografía, una composición); y, finalmente, la "estancia": a partir de la idea original, variantes de la frase que asumen que la posibilidad de mantener la calma llega a través de ciertas aficiones o prácticas (tomar té, leer un libro o ver películas: el meme se usa para reivindicar estas actividades); variantes simplemente absurdas; variantes irónicas (que niegan la posibilidad de seguir adelante según hemos visto); o las ideológicas, que ironizan sobre la posibilidad de mantener la calma y seguir adelante ante determinadas cuestiones sociales, políticas, etc. Como puede apreciarse, una de las características principales de la comunicación memética que aflora de su observación es la intertextualidad (Shifman, 2014: 109), que, por su importancia, abordaremos en detalle en el epígrafe siguiente.

\section{INTERTEXTUALIDAD. CONVENCIÓN Y DESVÍO}

Los memes, tanto de forma genérica como en sus manifestaciones concretas, son discursos fuertemente intertextuales, en la medida en que se construyen y se desarrollan unos en relación unos con otros (Milner, 2012: 31). "Los memes se comunican con los memes a través de nuevos memes" (Shifman, 2014: 814). Los mecanismos para realizar esto son los propios de las relaciones intertextuales: copia, parodia, apropiación, pastiche, distanciamiento irónico... (Shifman, 2014, 105; vid. D’Angelo, 2010). Ya hemos visto en el ejemplo del meme Keep Calm cómo solo se comprende la función comunicativa de las distintas apropiaciones si se conoce la instancia generadora original. De esta forma, la intertextualidad es el "puente" por el cual la información que contiene el meme se "recontextualiza" (Milner, 2013: 2363) y, de forma paradójica, a la vez que expande su información y adquiere con ella nuevos significados (a veces distintos u opuestos al mensaje original), al mismo tiempo consigue que el meme permanezca estable y se refuerce por una red de referencias 
cruzadas (Milner, 2012: 106). Pero la intertextualidad de los memes no es solamente interna, la condición de posibilidad de su propio desarrollo. Los memes además están fuertemente vinculados con la cultura popular o, más precisamente, de masas (Carroll, 2002), y se refieren continuamente a ella, hasta el punto de que esta relación intertextual es una de sus características principales (Segev, 2015: 421). Su cualidad intertextual, por tanto, no solo se relaciona con el hecho de que los memes se reproducen mediante la cita y la referencia (de un meme para consigo mismo y a veces a otros memes), sino que el contenido del meme suele poner en relación la idea o argumento que se pretende transmitir con un fenómeno de la cultura popular que hay que conocer para poder comprenderlo. La cultura pop ejerce por tanto de base cultural común (Shifman, 2014: 1409), un lenguaje, de hecho, desde el que expresar ideas a través de referencia intertextuales que van a ser comprendidas por los receptores que las comparten: "Collective symbols are the base of memes; they are the conventions by which transformation occurs" (Milner, 2012: 90). Si nos fijamos de nuevo en el ejemplo del meme Keep Calm, vemos que varias actualizaciones hacen referencias expresas a productos, personajes, etc. de la cultura popular: Disney, la Guerra de la Galaxias, o el humorista Chiquito de la Calzada. Solo si se sabe que hakuna matata es una expresión que aparece en la película El Rey León y que significa "vive y sé feliz" puede entenderse cómo encaja en sustitución de "carry on" y compone una suerte de actualización ingeniosa de la misma idea pasada por el imaginario de Disney ${ }^{14}$. Del mismo modo, solo el conocimiento contextual de que la imagen matriz es un cartel que tiene su origen Reino Unido y que la corona que aparece en ella es la británica, puede apreciarse la ironía de que se utilice para promover la independencia de Escocia. Sea como fuere, como consecuencia de esto, para entender buena parte de los memes que circulan por internet con sus referencias a la actualidad, bromas que se construyen sobre bromas previas e incluso referencias a otros memes, es preciso en ocasiones tener un grado de "alfabetización memética muy sofisticado" (Shifman, 2014: 1045): el necesario para saber cómo leer los distintos textos y crear los propios. "Transformative literacy means knowing what to combine and how in order to produce innovative new texts according to these contested subcultural

14. En realidad los memes utilizan para su desarrollo imágenes reconocibles en general, por tanto, también algunas tomadas de la alta cultura (Milner, 2013: 2363), siempre que tengan una cualidad icónica y fácilmente reconocible, casi siempre además para someterlas a algún tipo de manipulación irónica o paródica. 
standards" (Milner, 2012: 290). Pasar de simplemente compartir un meme a participar en el proceso de expansión significativa de éste solo es posible para una parte específica de la población. De ahí que haya llegado a hablarse de los memes en términos de "capital cultural" (en el sentido que Bordieu da a este sintagma, Nissenbaum, 2014) en el contexto de Internet, y que los memes, al igual que otras operaciones retóricas, devengan en una suerte de argot para iniciados, y una forma de iniciación y de control del acceso a determinados foros de la red (Nissenbaum, 2014: 2). Los memes por tanto implican ciertas técnicas, las alusiones a ciertas subculturas y etiquetas (Rowan, 2014: 419): en definitiva, al equilibrio entre norma o convención y sus posibles desvíos, tensión que es la que garantiza la correcta evaluación del valor u originalidad de estos con respecto de aquella. Esta doble naturaleza convencional/original (o de elementos originales en un marco convencional) es esencialmente una operación retórica. El Groupe $\mu$ entiende una convención como una forma sistemática de alteración que "se extiende sobre la totalidad del mensaje", como una "exigencia formal suplementaria que se añade a la gramática, la sintaxis, a la ortografía" (y en nuestro caso cabría añadir a otras normas que afectan por ejemplo a lo visual) y que sirve para atraer la atención sobre éste (1987: 87); frente a ella, el desvío es una alteración localizada e imprevista con respecto a la norma (1987: 86-87). La convención puede caracterizarse según el Groupe $\mu$, como sistemática, repartida, no sorpresiva y que hace aumentar la previsibilidad (1987: 88): estas cualidades convencionales, en un meme, son las que facilitan su reconocimiento y su cohesión a la hora de difundirse. El desvío se caracteriza como no sistemático, localizado, sorprendente y que hace disminuir la previsibilidad (1987: 88). Los desvíos son las mutaciones que algunos usuarios aportan en su actualización del meme (meme instance) y lo que permiten que estos sigan conservando su frescura y su utilidad comunicativa por el efecto de sorpresa. Es esta doble condición de elementos convencionales y desviados la que, desde un punto de vista sociológico, permite al público a través de los memes "simoultanely express both their uniqueness and their connectivity" (Shifman, 2014: 359) en lo que se ha descrito como "individualismo en red" (Shifman, 2014: 379): ser como todo el mundo, o al menos como un determinado grupo social (o tribu urbana) sin dejar de ser uno mismo a través de una aportación original.

Por otra parte, la convención, según hemos indicado, no solo refuerza 
los memes y permite su reconocimiento y su transmisión; también permite agruparlos y aventurar posibles clasificaciones o tipologías.

\section{TIPOLOGÍA DE LOS MEMES}

Desde una primera impresión, podría pensarse en clasificar los memes de internet por algunos de los rasgos formales de sus distintas actualizaciones; por ejemplo: imágenes fijas, imágenes fijas con texto (aquí habría que subdividir a su vez entre ilustraciones o fotografías; fotografías manipuladas o sin manipular, aparte otras subclasificaciones posibles); textos sin imagen; $G I F^{15}$; vídeos... No obstante, aunque es útil tener en cuenta los formatos en los que se propagan, estaríamos perdiendo de vista el rasgo fundamental del meme: que no conviene confundir a éste con sus instances, sus manifestaciones concretas. Pensando en los memes como esas constelaciones que artefactos en potencia, de estructuras discursivas, la tarea se vuelve más difícil y elusiva. Knobel y Lankshear (2006: 218), a partir de una muestra de 19 constelaciones de memes (con todas sus variantes) proponen una clasificación según el propósito del meme, con lo que dejan al margen las estructuras, formas y sus actualizaciones, y así distinguen cuatro grandes tipologías de memes que incluyen desde el comentario social y político al humor absurdo, bromas de diversas subculturas o propagación de bulos. Lo cierto es que una clasificación así, aunque pudiera resultar útil en algunos aspectos, no deja de resultar un tanto arbitraria. Más exhaustivo parece el estudio realizado por Elad Segev et alii (2015) sobre la base de 50 constelaciones de memes con su instances iniciales más unas veinte variantes de éstas, lo que da un total de 1050 objetos analizados (2015: 423). En él se llega a la conclusión de que lo que confiere unidad a los memes (y por tanto los hace susceptibles de una clasificación) son dos fuerzas principales: las cualidades esenciales específicas de cada familia por un lado; y una serie de cualidades de forma, contenido y stance (Shifman es uno de los coautores del artículo) que forman parte de las convenciones propias de la "meme culture" (2015: 418). En el artículo se vuelve sobre dos ideas que ya hemos indicado: que los

15. Se trata de pequeños clips que apenas superan los cuatro segundos de duración, compuestos de una sucesión de fotografías, dibujos, gráficos o fragmentos de vídeo que se reproducen en bucle hasta el infinito. Son a menudo acciones casi inacabadas, la captura de un instante que se repite como un mantra con efectos hipnóticos (Velázquez, 2016). 
memes forman familias (en este caso como alternativa a la metáfora de las constelaciones), y que un meme sólo puede definirse de modo retrospectivo (Segev, 2015: 418). En resumen: "so far, we have conceptualized internet memes as families of texts that share a similar quiddity. Yet each meme family also shares content and form characteristics with other meme families. Together they are organized into larger networks, shaping the digital culture at large" (2015: 420). También que, como hemos visto, las familias de memes se van construyendo, variante a variante, con lugares comunes, normas y convenciones recurrentes y, al mismo tiempo, con elementos únicos, originales, inesperados que se contraponen a éstas.

Tomemos el ejemplo de uno de los memes más antiguos de Internet y luego veamos otros posteriores que pueden emparentarse con él. Se trata del conocido como "El turista de la muerte" (Goriounova, 2013:13-14). El origen de este meme es el fotomontaje que un joven hizo a partir de una fotografía suya en la azotea de una las Torres Gemelas de Nueva York, donde añadió un avión acercándose. Fue una broma privada que envió a sus amigos, pero comenzó a difundirse con éxito por la red como si fuera una fotografía real ${ }^{16}$, que por tanto habría captado el momento en que se produce el atentado terrorista del 11 de septiembre con el añadido dramático del sujeto de la imagen que no sabe que está a punto de morir. Pronto se hizo manifiesta la condición fraudulenta de la fotografía y comenzaron a proliferar las variantes, que consistían en fotomontajes de esta persona (cuya imagen se tomaba de la fotografía primera) en momentos culminantes de otras tragedias históricas.

16. El joven, un húngaro llamado Péter Guzli, tuvo que acabar pidiendo disculpas públicas por el daño que hubiera podido causar a las víctimas por la posible trivialización del atentado mientras reiteraba en todo momento que él únicamente había hecho circular el montaje entre sus amistades. 


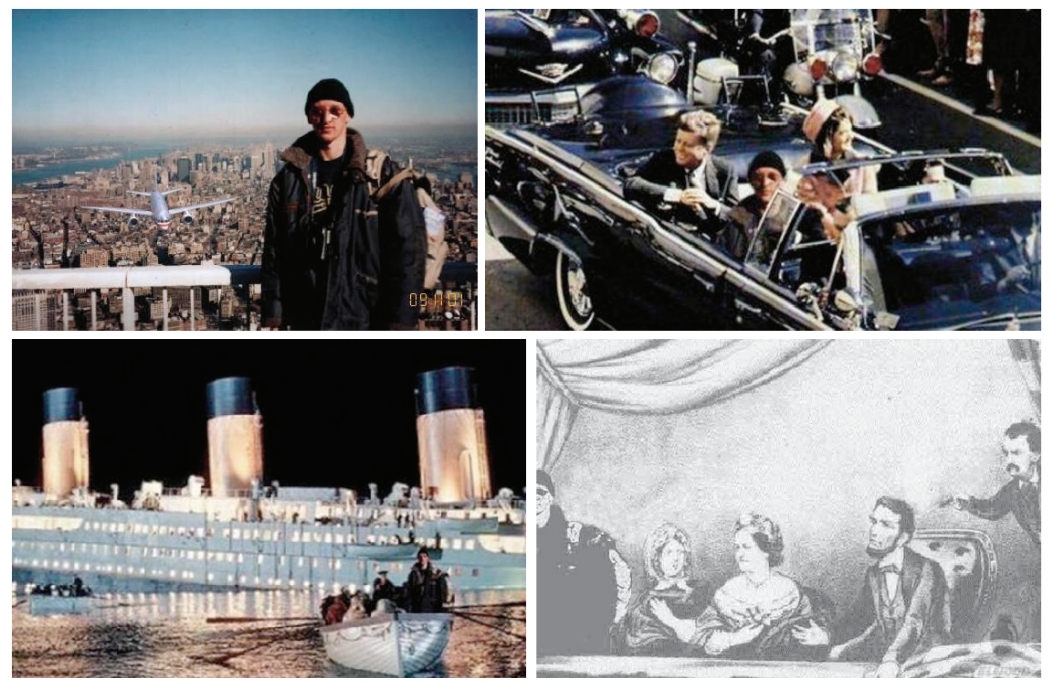

El propósito de este meme no parece ser otro que el del humor absurdo, quizá con el añadido de una crítica hacia el exceso de credulidad en relación con las imágenes que circulan por Internet. Este meme puede ponerse en relación con otros cuatro: en 2009, apareció una fotografía del por entonces presidente de la República francesa Nicolas Sarkozy que lo situaba de joven en Berlín justamente en la noche histórica de 1989 de la caída del Muro, en el lugar de los hechos y participando de la acción. La fotografía se descubrió como igualmente fraudulenta y dio lugar a una serie de variantes meméticas con una dinámica similar: montajes con Sarkozy en diferentes momentos culminantes. Otro tanto le ha sucedido al primer ministro israelí Benjamin Netanyahu con una foto manipulada donde se le hacía aparecer en el reencuentro entre el soldado israelí Gilad Shalit y su padre (que lo abraza) después de cinco años de cautiverio por Hamas, con variantes meméticas igualmente disparatadas. En España, el periodista Carlos Herrera se hizo un selfie frente a la entrada del pub Bataclan, que acababa de ser objeto del atentado terrorista, junto a las ofrendas improvisadas que había ido depositando la gente, lo que a una parte de la opinión pública de las redes sociales le pareció una fotografía impropia, y de nuevo comenzó el proceso de situar, en este caso el rostro del periodista tomado de esta foto original, en el escenario de diversas tragedias como si se estuviera realizando el consabido selfie en ellas. 

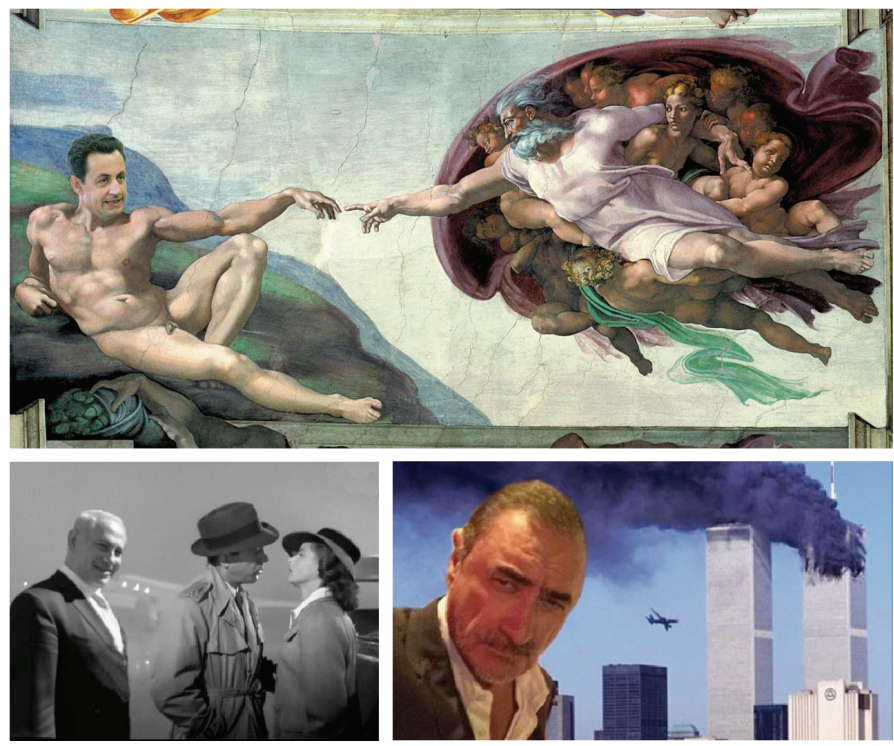

Por último, en 2005, la felicitación navideña oficial de la familia real española fue una imagen de los entonces reyes Juan Carlos I y Sofía con sus nietos; la fotografía era obviamente un montaje - además bastante burdo - donde los distintos miembros habían sido tomados de otras fotografías y añadidos de forma digital. Esto generó una polémica que obligó a la casa real a confirmar que, en efecto, no se trataba de un posado. Pronto empezaron a surgir y a difundirse por internet una serie de montajes fotográficos a partir del montaje original ${ }^{17}$ : algunos de ellos puramente humorísticos y absurdos, otros con una clara intención satírica. 


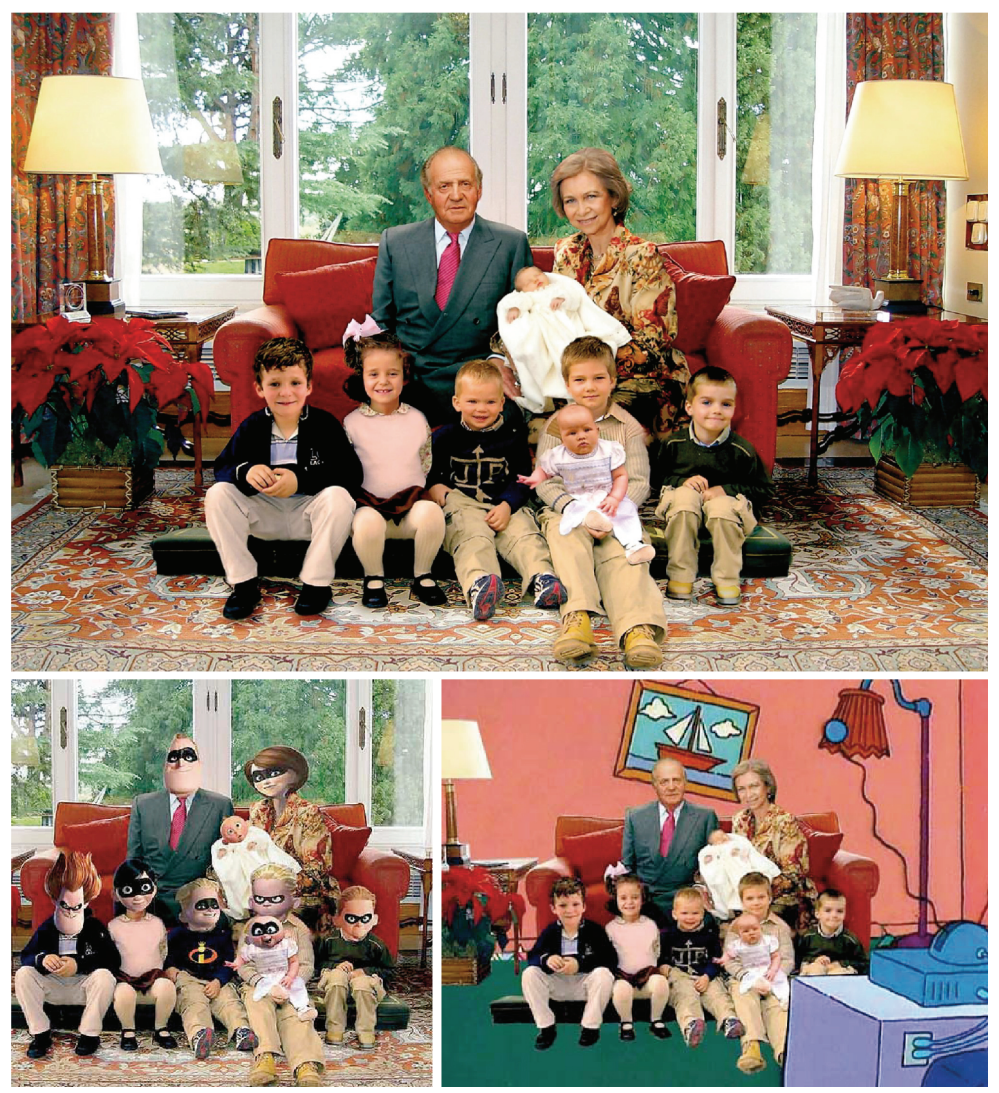

En los casos de los memes del "turista de la muerte", Sarkozy, Netanyahu y la familia real española, el propósito parece ser el de desenmascarar un fraude (con una clara intencionalidad de sátira o crítica al gobernante en los tres últimos casos); en el del periodista Carlos Herrera, se trataría más bien de criticar una actitud que se considera fuera de lugar. No obstante, nótese que, aparte de la intención satírica y moralizante común, el procedimiento es el mismo; existe una clara convención retórica: una yuxtaposición anómala de elementos que obliga a una reevaluación de la imagen que estamos contemplando y que busca un efecto de tipo irónico o paródico. El desvío particular consiste en el hallazgo concreto de cada usuario al encontrar un escenario aún más abracadabrante para los protagonistas de los montajes, que ya depende para su éxito del kairos con 
el que haya dicha variante haya sido ideada. La evolución de estos memes funciona además por acumulación: las sucesivas imágenes (genuinas hipérboles visuales) obligan a las nuevas a ser cada vez más delirantes, en una suerte de más difícil todavía que, tomado en su conjunto, nos sugiere una idea de clímax retórico.

Para nuestro acercamiento, por lo demás introductorio, más que buscar una clasificación de familias concretas, nos interesan más esas otras cualidades genéricas que en el artículo de Segev se definen como constitutivas de la cultura general de internet. En particular, algunas particularmente retóricas como la yuxtaposición inesperada, incongruente o anómala (Knobel and Lankshear, 2006; 215; Shifman, 2014: 336; Hungtington, 2016: 86), o directamente el empleo de tropos (Hungtington, 2016), casi siempre de carácter visual. Por tanto, vamos a fijarnos en una disposición formal característica de muchas familias de memes, distinta de las vistas hasta ahora (que consistía tan solo en la manipulación de una imagen) cuyo contenido o propósito puede estar muy alejado entre sí aunque su estructura y disposición formal es idéntica. Se trata de un template (planilla o estructura) denominada macro $^{18}$.

\subsection{Macros y emblemas: palabra e imagen}

La estructura semiótica macro, en el contexto de los memes, consiste en una imagen fija, acompañada de un texto inserto en esta (Shifman, 2014: 1162; Hungtington, 2016: 79). En ocasiones, este texto suele estar dividido en dos partes: una prótasis o proposición en la parte superior de la imagen, y una apódosis a modo de conclusión, refutación o paradoja en la parte inferior. Existen toda una serie de familias de memes que se desarrollan con este formato, en las que, a partir de una misma fotografía fija (de una animal, de un famoso, o de alguien desconocido en alguna situación particular o con algún rasgo característico), cada usuario decide con qué texto acompañar a esa imagen ${ }^{19}$.

18. A este tipo de convención memética se le denomina así por una funcionalidad existente en los primeros foros online que permitía introducir texto superpuesto a las imágenes. Este texto se llamaba "macro" (Rowan, 2015: 299).

19. El origen de esta forma de memes parece ser uno de ellos, el denominado "advise dog", esto es "el perro consejero". Consiste en la imagen de un perro con un fondo de arcoíris que da consejos de tipo humorístico o emotivo. A partir de aquí se desarrollo toda una subfamilia de animales consejeros, o que "decían cosas, y de ahí se pasó a imágenes de seres humanos, famosos o no, en distintas situaciones" (Shifman, 2014: 112-113), también acompañados de un texto. 

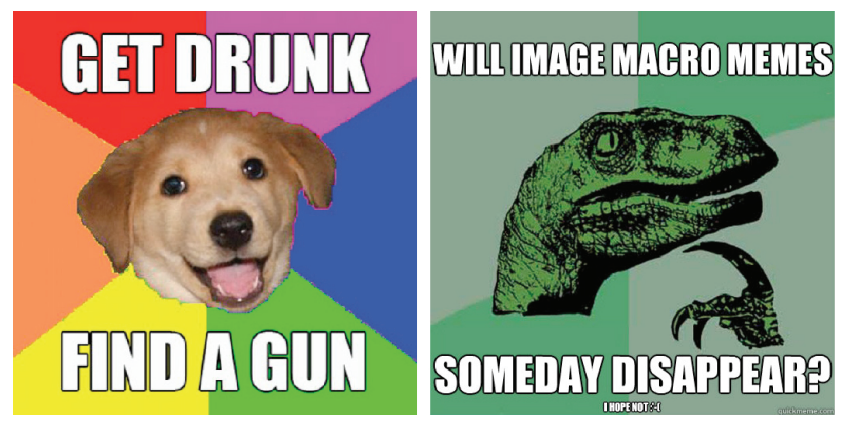

Nótese que la estructura discursiva (multimodal) imagen/texto preexiste como forma posible, y que es en el momento en que el emisor, acorde con sus necesidades o por el simple estímulo de haberla visto, escoge una imagen específica sobre la que superponer un texto acorde con sus necesidades, es cuando está contribuyendo a perpetuar un meme determinado. Esta fórmula es la idea más común que se tiene de meme (hasta al punto de que, por lo general, en el habla cotidiana es a estas imágenes/texto a las que se denomina, impropiamente, memes); también los principales programas o aplicaciones para generar memes consisten en un catálogo de imágenes a los que se les puede superponer de forma sencilla el texto correspondiente; el usuario solo tiene que escoger la imagen que prefiera (que ya viene determinada en el catálogo del programa por su éxito precedente como imagen memética) y añadir el texto. La citada convención por "agregación de microimitaciones" (Rowan, 2015: 305) ha hecho que incluso la tipografía escogida para dichos textos sea una muy concreta, la impact, y resultaría raro (fuera de la convención) una materialización de alguno de estos tipos de meme que empleara otra (Huntington, 2016: 79).

En estos casos se produce una cualidad semiótica fundamental para la comprensión del meme: la imagen implica, o bien una cara (humana o animal), especialmente expresiva, que sugiere de forma manifiesta (y estereotipada) algún tipo de emoción (perplejidad, asco, hilaridad, horror), casi siempre ridícula o risible ${ }^{20}$; en otras ocasiones, la imagen consiste en

20. Está comenzando en internet la tendencia a usar estas imágenes, sin ningún texto de acompañamiento, como reacción a un determinado comentario. Ante una afirmación discursiva discutible, en lugar de con otro texto, se replica con una imagen en la que aparece un rostro mostrando una expresión elocuente, por ejemplo de escepticismo. Podría decirse que se trata de una evolución o sofisticación del empleo de emoticonos (rostros que 
una acción congelada en el tiempo (Shifman, 2014: 990), también de una persona o un animal en una situación inestable, extraña, y, de nuevo, casi siempre ridícula o hiperexpresiva (podríamos decir, de hecho se busca lo contrario de la serenidad que Lessing en su Laocoonte prescribía para las imágenes fijas). Además, estas imágenes presentan una cualidad retórica fundamental: en algunos casos funcionan como un ethos visual en la medida en que emplean el rostro de un personaje famoso, al que se asocian determinados valores, que denota una actitud concreta y lo hace de modo firme y convincente; en realidad, el rostro ni siquiera tiene que ser el de un famoso para que cumpla esta función, sobre todo cuando el meme se utiliza, como sucede con frecuencia, para transmitir la idea (argumentativa) del escepticismo que produce una determinada afirmación.
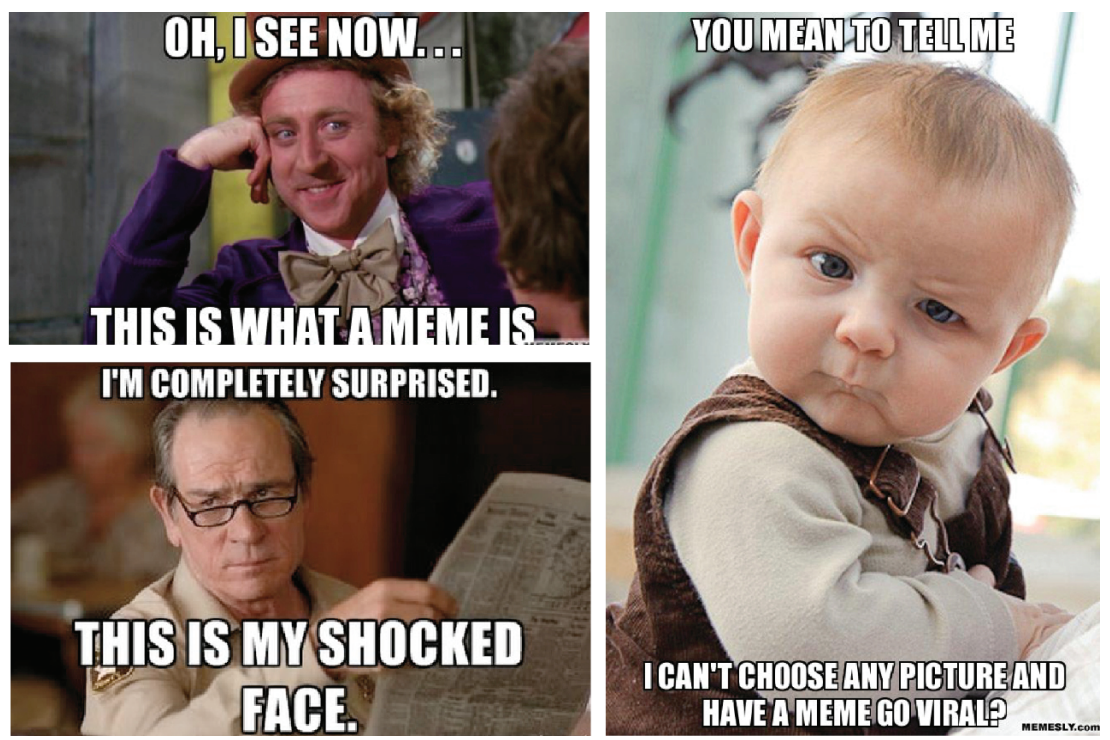

Por lo mismo, en ocasiones (sobre todo en el caso de memes serios y con una clara intencionalidad política), la imagen tiene un pathos que, en cuanto visual, resulta más persuasivo y poderoso. Para Milner, el "99\%" de las imágenes de los memes "relied upon pathos to facilitate engagement"

intentan mostrar emociones para subrayar o matizar lo dicho por escrito) y que, por cierto, también son memes (Davidson, 2012: 124-125). 
(2013: 2372). Por ejemplo, cuando se usa la imagen de un niño desnutrido para denunciar, a través del texto, alguna conducta frívola del primer mundo.

Es sobre estas imágenes sobre las que el texto añadido cobra un sentido, siempre de carácter incongruente o paradójico. Así, encontramos en estas familias de memes una relación entre texto e imagen con la característica que señalaba Barthes en relación con la retórica de las imágenes publicitarias (con las que, evidentemente, este tipo de memes guardan muchas similitudes formales): la imagen aquí no sirve para ilustrar el texto y reducir sus posibles connotaciones a una denotación, sino que, por el contrario, "the text loads the imagen, burdening it with a culture, a moral, an imagination" (Barthes, 1977: 26); no obstante, aquí el texto tampoco reduce la foto, como en el caso de los pies de las fotografías en el periodismo, sino que la amplifica y abre su significado por la vía de la paradoja. En este sentido, los memes operan de forma análoga al célebre cuadro de Magritte Ceci n'est pas une pipe donde, según Foucault ${ }^{21}$, la imagen y el texto, en lugar de crear una suerte de doble cifrado, de dos mandíbulas de un cepo con el que atrapar el sentido, reabre la trampa y dejan escapar a éste al no compartir un suelo común (Mitchell, 1994: 70). También en este sentido, resulta muy sugestiva la comparación entre este tipo de memes con otro discurso híbrido de ingenio muy anterior, con el que nos parece guardan interesantes similitudes formales y de intención dentro de sus obvias y radicales diferencias formales y sociohistóricas: el emblema. Es indudable que ambos tipos de texto híbrido, "mixto o logoicónico" (Rodríguez, 1995: 21) pertenecen a lo que Rodríguez de la Flor ha denominado "el complejo dominio globalizado de lo icónico lingüístico; las plurales tradiciones que implican a los dos sistemas de signos más complejos - los pictóricos y los verbales - allá donde éstos se hayan venido a encontrar sobre la superficie de un campo de representación". (1995: 11-12). Si esta relación entre emblemas y memes puede parecer excesiva, basta con ver cómo alguna de las principales

21. Este cuadro de Magritte participa de las características del meme pero, obviamente, no lo es en su condición de objeto único. No obstante, si lo ponemos en relación con otras variaciones sobre el mismo tema realizadas por el propio Magritte, (Mitchell, 1994: 72-73) y, sobre todo si atendemos a la variación que sobre este cuadro realizó el colectivo Preiswert Arbeitskollegen, donde puede verse una pistola pintada con unas características de color, textura, etc. muy similares al pipa de Magritte con la inscripción "esto sí es una pipa”, encontraríamos el principio de una acción memética, siempre que comenzara a partir de aquí un juego de reproducción y sucesivas variaciones. 
"peculiaridades" que les atribuye Enrique Gastón (2010) a aquéllos casan sin problema con las éstos: Para Gastón, los emblemas reflejan mensajes cerrados de forma sintética, con una tendencia a la simplificación, y están pensados para ser repetitivos, "utilizan fundamentalmente la técnica de la repetición" (2010: 258). Además, "por lo que tienen de simbólico codificado, reducirían la necesidad de pensar" (258). En última instancia, la emblemática sería un agente socializador, de formación de actitudes: "Aquí los emblemas coinciden con los epigramas, los aforismos, los refranes $[\ldots] \mathrm{y}$, por supuesto, ciertas formas de propaganda y publicidad" (Gastón, 2010; 259; Rodríguez, 1995: 287) ${ }^{22}$. Aparte, Rodríguez de la Flor da cuenta de un tipo particular de emblema, denominado silente que consistía en imágenes con un espacio destinado para un "texto potencial, que está aún ignoto, como en reserva en la imaginativa de un receptor todavía por venir" (1995: 44); algo muy similar a los repertorios de imágenes de las aplicaciones para la creación de memes que ya hemos citado, donde en efecto el receptor solo tiene que añadir el texto. A finales del s. XVII comienza ya un proceso de estereotipación de los emblemas, con la consiguiente elaboración de diccionarios de símbolos que buscaban "posibilitar la transcripción figurativa de un pensamiento estabilizado" (Rodríguez, 1995: 56), y de repertorios de iconos "vinculados a un sentido prioritario", como, por ejemplo, la Iconología de Ripa (1995: 56); este proceso de degradación y estereotipación va unido a demás, de forma muy significativa, a composiciones "degradadas, incluso chistosas y chocantes" (Rodríguez, 1995: 54). Según Rodríguez de la Flor, con este proceso de degradación el emblema degenera en "estereotipo", en "una forma vacía y disponible" (1995: 362): "queda dispuesto para multiplicar banal y gratuitamente su contorno — su mera superficie formal_" (1995: 363). Y añade: "en adelante, los símbolos serán solo los operadores narrativos de un discurso en cierto modo banal, masificado [...] charada, juego significante que se ofrece sin drama" (1995: 366). Fuera de contexto, como aparecen aquí, estas citas podrían aplicarse sin ninguna violencia a la descripción de los memes. En realidad, según esta descripción y proceso histórico, los emblemas son memes propiamente dichos según los describe Dawkins, aunque obviamente no lo sean de Internet.

22. Rodríguez de la Flor considera una continuación de los emblemas a las chapas (1995: 368), que son sus mensajes, imágenes o mezcla de ambos de carácter ingenioso y su difusión (analógica, eso sí) son a su vez un claro precedente de los memes. 
Esta afinidad entre memes y emblemas se explica, a nuestro juicio, porque, más allá de las diferencias formales, sociohistóricas, ideológicas y de contexto, ambas realidades semióticas se rigen por una technē retórica para alcanzar un fin expresivo y persuasivo. Los emblemas perseguían "imponerse masivamente, acríticamente diríamos, al espectador y lograr captar así su voluntad, operando más en el terreno de la persuasión emocional que en el del conocimiento racionalizado" (Rodríguez, 1995: 26). Según José María Maravall (apud. Rodríguez): "pretendían producir una acción directa sobre el ánimo valiéndose de medios sensibles" (1995: 26). En el emblema, hay un efecto mutuo entre figura y texto que propicia la actualización del sentido en forma de circuito de interpretación mutua (Rodríguez, 1995: 56). Así también los memes; y la forma que tienen de lograrlo es gracias la estructura descrita donde las citadas yuxtaposición anómala y el tropo desempeñan su labor retórica.

\section{YUXTAPOSICIÓN ANÓMALA, TROPO, SÍMBOLO}

Según hemos indicado y hemos podido ver en los casos (vid. apartado 5), "a fundamental feature of many memetic photos is a striking incongruity bewteen two or more elements in the frame" (Shifman, 2014: 961), a lo que podemos añadir, en el caso de los macros, la incongruencia entre la imagen y el texto que la acompaña. Esto genera un "irritating dialogism" (Huntington, 2016: 85) que busca una respuesta por parte de lector. En su proceso de yuxtaposición, los memes entroncan de este modo con lo que Susan Sontag describió como un "modo de sensibilidad" que comienza en el siglo XX (Sontag, 1961: 347-348), y que incluye en su seno al surrealismo, al dadaísmo, también al arte conceptual, el arte povera, los happenings e, incluso, prácticas en un principio alejadas del arte como el psicoanálisis, y que culmina en el XXI con arte conceptual, o los grafitti de Bansky. Según Sontag, dicha sensibilidad "responde al propósito de destruir significados convencionales y crear nuevos significados o contra significados mediante la yuxtaposición radical (el 'principio del collage')" (Sontag, 1961: 348). Se trata, en efecto, de aunar realidades disímiles para, juntas, obligar al receptor a resolver la aparente incongruencia y encontrar un sentido. Esta operación nos remite, en última instancia, al funcionamiento propio de las figuras retóricas según el Groupe $\mu$ : éste entiende la retórica como "la transformación reglada de los elementos de un enunciado, de tal manera 
que en el grado percibido de un elemento manifestado en el enunciado, el receptor deba superponer dialécticamente un grado concebido" (1993: 232). Dicha operación presenta tres fases: "producción de una desviación que se llama alotopía, identificación y nueva evaluación de la desviación" (Groupe $\mu, 1993:$ 232). Digamos que en un contexto esperable, de norma o grado cero, se produce una brusca frustración de las expectativas que obliga a una reevaluación: éste es el procedimiento de descontextualización al que nos venimos refiriendo y que se vincula con la idea del meme como elemento significativo dotado de cualidades esperables, convencionales, a partir de las cuales se reevalúan los elementos originales u anómalos que ha aportado cada variante. En el meme se nos presenta algún elemento reconocible a primera vista; no obstante, algo capta nuestra atención: o bien elementos anómalos, ortográficos ${ }^{23}$, visuales (como la presencia incongruente de una figura en un lugar donde no le corresponde) $)^{24}$,

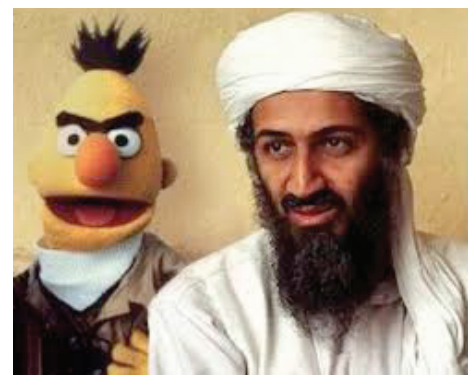

o bien la incongruencia entre la imagen y el texto que la acompaña, según hemos visto en las imágenes macro. Esto obliga al receptor a una readecuación de sus expectativas; en palabras de Shifman, "a rellenar los huecos o resolver el puzle" (Shifman, 2014: 941), lo que conduce a la comprensión del argumento que subyace al meme y, por lo general, al humor (por lo demás, es el propio mecanismo retórico de los chistes el que participa de este mecanismo retórico de resolución de una incongruencia) ${ }^{25}$.

23. Por ejemplo la expresión "ola ke ase", deformación de "Hola, qué haces" y que deviene en meme en la medida en que los usuarios la comparten, la recontextualizan, la añaden a imágenes, la modifican ("Ola ke dise, Ola ke kiere"). Incluso un meme tan trivial puede cargarse de connotaciones ideológicas cuando se emplea, con su aparente ingenuidad, para interpelar a un político tras una actuación ("hase") o unas declaraciones ("dise") polémicas.

24. Uno de los primeros memes fue el conocido como "Bert is evil" donde el personaje de Barrio Sésamo (conocido en España como Blas) aparecía junto a figuras históricas reprobables o en actitudes comprometidas, en un ejemplo de yuxtaposición anómala.

25. Como es sabido, Freud en El chiste y su relación con el inconsciente atribuye un mecanismo de 
La función de estas yuxtaposiciones incongruentes suele ser la de la ironía, bien con intención humorística, bien con intención argumentativa. Huntington habla de la creación de genuinos entimemas visuales que se producen por la necesidad de interpretar el meme (2016: 87). En el caso ya visto de los memes de Sarkozy o Netanyahu, éste podría ser: si estos políticos nos han mentido una vez acerca de sus actividades, lo harán siempre: la imagen disparatada no es más falaz que otras que veamos de ellos con apariencia perfectamente verosímil ${ }^{26}$.

Lo incompleto del mensaje asimismo también favorece su posterior remezcla y difusión, porque dado que a través la incongruencia de partida del mensaje, de su falta de cierre, es por donde pueden introducirse, por imitación, las variantes.

\section{CONCLUSIONES}

Como hemos tratado de mostrar, la naturaleza y las características de los memes hacen de la retórica una vía especialmente eficaz de descripción y comprensión de este fenómeno, lo que no ha pasado desapercibido a algunos de sus estudiosos (vid. Hugntington, 2016; Jenkins, 2014). Desde el momento en que los memes se definen, según hemos visto, como formas de persuasión, artefactos discursivos de expresión y discusión pública (Shifman, 2014: 1267) que buscan hacer reír y sorprender por el ingenio, pero también persuadir a través de un discurso en ocasiones multimodal (o multimedia) que presenta una serie de manipulaciones para producir unos efectos, estos son susceptibles de ser analizados desde un punto de vista retórico (Hungtington, 2016: p. 79). Los memes de internet cumplen algunas de las principales cualidades retóricas señaladas por Barthes (1994: 8688): son una práctica lúdica; implican una technē, esto es, un conocimiento especializado de las reglas para su producción y lectura; son un lenguaje que contiene elementos y características susceptibles de ser clasificados y de generar un metadiscurso; $\mathrm{y}$, por último, los memes constituyen en cuanto discurso una práctica social que distingue a quienes lo dominan de quienes no (Shifman, 2014: 333) y que, como ciertos tipos de jerga, permite a sus usuarios reconocerse entre sí y eventualmente excluir a los no iniciados.

condensación propio de los tropos a los chistes, al igual que había hecho con los sueños.

26. Como entimema que es, dicho razonamiento, u otros análogos que pudieran extraerse de otros memes, no tienen por qué ser verdaderos, tan solo verosímiles y, por ende, persuasivos. 
Los memes han generado de este modo una nueva forma de comunicación social y comentario, las más veces humorístico y despreocupado, de la actualidad. En el ámbito político, no obstante, los memes han supuesto una forma de participación ciudadana en la discusión pública que autores como Milner (2013: 2361) perciben como dinámica, activa, comprometida y polifónica, que se encuentra más allá de los cauces de expresión habituales (la prensa y los medios de comunicación audiovisuales), más restringidos, y que pueden contribuir eventualmente a la subversión de un discurso dominante. No obstante, la forma de difusión de los memes, a través de redes sociales, corre el riesgo de generar el efecto conocido como "cámaras de eco" (Milner, 2013: 2362) según el cual los distintos grupos ideológicos solo buscan, crean, modifican y comparten con sus afines memes que contribuyen a confirmar sus propios sesgos y prejuicios ideológicos, con lo cual la supuesta polifonía o enriquecimiento de la discusión pública queda reducida a monólogos para los ya convencidos. Por otra parte, los memes también presentan los problemas propios de la toda comunicación retórica desde sus orígenes: el riesgo de la demagogia, y los argumentos fundados en el pathos y verosimilitud por encima de la racionalidad y la veracidad. Sea como fuere, los memes de Internet se han convertido en una suerte de capital cultural que comenzó siendo seña de algunas subculturas vinculadas a Internet y sus prácticas pero que ya ha permeado, probablemente de forma irreversible, al resto de la sociedad.

\section{REFERENCIAS BIBLIOGRÁFICAS}

BARTHES, R. (1977). Image. Music. Text. New York: Hill and Wang. (1994). La aventura semiológica. Barcelona: Planeta-De Agostini.

BERLANGA, I. et alii (2016). "Facebook y la metáfora. La comunicación retórica en las redes sociales digitales". Signa 26, 413-431.

BUSTOS, J. (2016). "Esto no es serio". El Mundo, 22 de enero, http://www. elmundo.es/opinion/2016/01/22/56a129a1268e3ed2018b4575.html [26/08/2016].

CARROLL, N. (2002). Una filosofia del arte de masas. Madrid: Antonio Machado Libros.

D'ANGELO (2010). "The Rhetoric of Intertextuality". Rethoric Review 
29.1, 31-47.

DAVIDSON, P. (2012). "The Language of Internet Memes". En The Social Media Reader, Michael Mandiberg (ed.), 120-134. New York: New York University Press.

DAWKINS, R. (2002). El gen eogísta. Las bases biológicas de nuestra conducta. Barcelona: Salvat.

GASTÓN, E. (2010). "Algunas implicaciones sociológicas de los emblemas”. Emblemata. Revista aragonesa de emblemática 16, 257269.

GORIUNOVA, O. (2013). "The Force of Digital Aesthetics: on Memes, Hacking, and Individuation". Zeitschrift für Medienwissenschaft V, 8, http://www.academia.edu/3065938/The_force_of_digital_aesthetics_on_memes_hacking_and_individuation [26/08/2016].

KNOBEL, M. y C. LANKSHEAR (2006). "Online Memes, Affinities, and Cultural Production”. En A New Literacies Sampler, Michele Knobel y Colin Lankshear (eds.), 199-227. New York: Peter Lang.

GARCÍA, D. (2014). "Las imágenes macro y los memes de Internet: posibilidades de estudio desde las teorías de la comunicación". Paakat. Revista de tecnología y sociedad 6, http://goo.gl/7O7OV0 [10/01/2017].

GROUPE $\mu$ (1987). Retórica general. Barcelona: Paidós. (1993). Tratado del signo visual. Madrid: Cátedra.

HUNGTINGTON, H. (2016). "Pepper Spray Cop and the American Dream: Using Synecdoche and Metaphor to Unlock Internet Memes' Visual Political Rhetoric". Communication Studies 67.1, 77-93.

JAKOBSON, R. (1981). Lingüística y poética. Madrid: Cátedra.

JENKINS, E. S. (2014). "The Modes of Visual Rhetoric: Circulating Memes as Expresions". Quartlerly Journal of Speech 100.4, 442466.

JENKINS, H. (2013). Spreadable Media: Creating Value and Meaning in a Networked Culture. New York: New York University Press.

MILNER, R. M. (2012). The World Made Meme: Discourse and Identity in Participatory Media Culture, dissertation, University of Kansas, https://kuscholarworks.ku.edu/bitstream/handle/1808/10256/Milner_ku_0099D_12255_DATA_1.pdf[14/09/2016].

(2013). "Pop Polyvocality: Internet Memes, Public Participation, and the Occupy Wall Street Movement". International Journal of 
Communication 7, 2357-2390.

(2015). "Memes are Dead; Long live Memetics “. Culture Digitally, 27 de octubre, http://culturedigitally.org/2015/10/01-memes-aredead-long-live-memetics-by-ryan-m-milner [26/08/2016].

MITCHELL, W. J. T. (1994). Picture Theory. Chicago: Chicago University Press.

NISSEMBAUM, A. y Limor Shifman (2014). "Internet Memes as Contested Cultural Capital: The Case of 4chan's /b/ Board". New Media \& Society 1,19, 2-19.

PATO, I. (2016). "Podíamos. O cómo conquistar el Estado con memes y lágrimas". Playground, 19 de enero, http://www.playgroundmag.net/ noticias/actualidad/Antonio_Gramsci-Podemos-Pablo_IglesiasInigo_Errejon-Juan_Carlos_Monedero_0_1684631521.html [26/08/2016].

RODRÍGUEZ, D. (2013). Memecracia. Los virales que nos gobiernan. Barcelona: Gestión 2000.

RODRÍGUEZ DE LA FLOR, F. (1995). Emblemas. Lecturas de la imagen simbólica. Madrid: Alianza.

ROWAN, J. (2015). Memes. Inteligencia idiota, política rara y folclore digital. Kindle. Madrid: Capitán Swing.

SEGEV, E. et alii (2015). "Families and Networks of Internet Memes: The Relationship Between Cohesiveness, Uniqueness, and Quiddity Concreteness". Journal of Computer-Mediated Communication 20, 417-433.

SHIFMAN, L. (2014). Memes in Digital Culture. Kindle. Cambridge, Massachusetts: MIT University Press.

SONTAG, S. (1961). Contra la interpretación. Madrid: Alfaguara.

VELÁZQUEZ, J. (2016). "GIF. La vida en bucle". Ahora 34, https://www. ahorasemanal.es/gif-la-vida-en-bucle [26/08/2016].

Recibido el 1 de enero de 2017.

Aceptado el 3 de marzo de 2017. 
